\title{
EIGENVALUE MULTIPLICITIES FOR SECOND ORDER ELLIPTIC OPERATORS ON NETWORKS
}

\author{
JOACHIM VON BELOW AND JOSÉ A. LUBARY
}

\begin{abstract}
We present some general bounds for the algebraic and geometric multiplicity of eigenvalues of second order elliptic operators on finite networks under continuity and weighted Kirchhoff flow conditions at the vertices. In particular the algebraic multiplicity of an eigenvalue is shown to be strictly bounded from above by the number of vertices if there are no eigenfunctions vanishing in all nodes, and to be bounded from above by the number of edges if there are such eigenfunctions.
\end{abstract}

Mathematics subject classification (2010): 34B45, 34L20, 05C50, 35J25, 34L10.

Keywords and phrases: Elliptic operators on networks, eigenvalue multiplicities, adjacency and transition operators.

\section{REFERENCES}

[1] J. VON BELOW, A characteristic equation associated to an eigenvalue problem on $c^{2}$-networks, Lin. Alg. Appl. 71 (1985), 309-325.

[2] J. VON BELOw, Kirchhoff laws and diffusion on networks, Lin. Alg. Appl. 121 (1989), 692-697.

[3] J. vON BELOw, Sturm-Liouville eigenvalue problems on networks, Math. Meth. Appl. Sci 10 (1988), 383-395.

[4] J. vON BeLow, Parabolic network equations, 2nd ed., Tübingen, 1994.

[5] J. VON BELOW AND J. A. LUBARY, Harmonic functions on locally finite networks, Results in Math. 45 (2004), 1-20.

[6] J. VON BELOW AND J. A. LubARY, The eigenvalues of the Laplacian on locally finite networks, Results in Math. 47 (2005), 199-225.

[7] J. VON BELOW AND J. A. LUBARY, The eigenvalues of the Laplacian on locally finite networks under generalized node transition, Results in Math. 54 (2009), 15-39.

[8] J. VON BELOW AND J. A. LUBARY, Isospectral infinite graphs and networks and infinite eigenvalue multiplicities, Networks Het. Media. 4 (2009), 453-468.

[9] J. VON BELOW AND J. A. LUBARY, Eigenvalue asymptotics for second order elliptic operators on networks, Asymptotic Analysis 77 (2012), 147-167.

[10] N. L. Biggs, Algebraic graph theory, Cambridge Tracts Math. 67, Cambridge University Press, 1967.

[11] S. Cardanobile And D. Mugnolo, Parabolic systems with coupled boundary conditions, J. Differential Equ. 247 (2009), 1229-1248.

[12] D. M. CvetKović, M. Doob And H. Sachs, Spectra of graphs, Academic Press, New York, 1980.

[13] M. KRAmAR FiJaVŽ, D. Mugnolo AND E. Sikolya, Variational and semigroup methods for waves and diffusion in networks, Appl. Math. Optim. 55 (2007), 219-240.

[14] J. A. LUBARY, Multiplicity of solutions of second order linear differential equations on networks, Lin. Alg. Appl. 274 (1998), 301-315.

[15] J. A. LUBARY, Multiplicidad y valores propios no reales en problemas de contorno para ecuaciones diferenciales sobre redes, Doctoral Thesis UPC Barcelona, 2000.

[16] J. A. LuBARY, On the geometric and algebraic multiplicities for eigenvalue problems on graphs, in: Partial Differential Equations on Multistructures, Lecture Notes in Pure and Applied Mathematics Vol. 219, Marcel Dekker Inc., New York, 2000, 135-146. 
[17] G. LuMER, Connecting of local operators and evolution equations on networks, in: Potential Theory Copenhagen 1979, Lect. Notes Math. Vol. 787, J. Springer Berlin, 1980, 219-234.

[18] D. Mugnolo, Parabolic systems and evolutions equations on networks, Habilitationsschrift Universität Ulm 2010.

[19] S. NicAise, Spectre des réseaux topologiques finis, Bull. Sc. Math. $2^{e}$ Série 111 (1987), 401-413.

[20] R. J. WILSON, Introduction to graph theory, Oliver \& Boyd Edinburgh, 1972. 